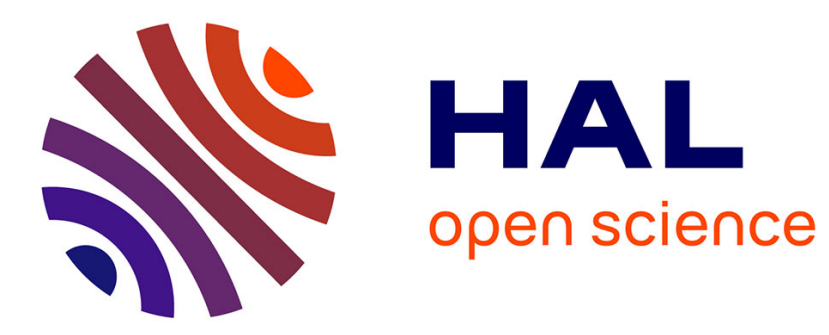

\title{
Microvascular reconstructions after extensive soft tissue sarcoma resections in the upper limb
}

\author{
I. Barner-Rasmussen, P. Popov, T. Böhling, C. Blomqvist, E. Tukiainen
}

\section{To cite this version:}

I. Barner-Rasmussen, P. Popov, T. Böhling, C. Blomqvist, E. Tukiainen. Microvascular reconstructions after extensive soft tissue sarcoma resections in the upper limb. EJSO - European Journal of Surgical Oncology, 2010, 36 (1), pp.78. 10.1016/j.ejso.2009.08.003 . hal-00556320

\section{HAL Id: hal-00556320 \\ https://hal.science/hal-00556320}

Submitted on 16 Jan 2011

HAL is a multi-disciplinary open access archive for the deposit and dissemination of scientific research documents, whether they are published or not. The documents may come from teaching and research institutions in France or abroad, or from public or private research centers.
L'archive ouverte pluridisciplinaire HAL, est destinée au dépôt et à la diffusion de documents scientifiques de niveau recherche, publiés ou non, émanant des établissements d'enseignement et de recherche français ou étrangers, des laboratoires publics ou privés. 


\section{Accepted Manuscript}

Title: Microvascular reconstructions after extensive soft tissue sarcoma resections in the upper limb

Authors: I. Barner-Rasmussen, P. Popov, T. Böhling, C. Blomqvist, E. Tukiainen

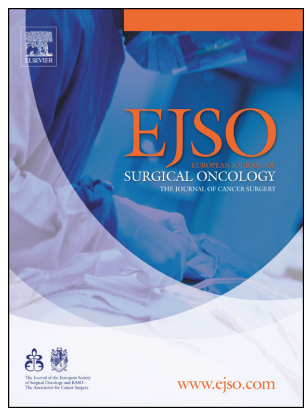

PII:

S0748-7983(09)00435-1

DOI:

10.1016/j.ejso.2009.08.003

Reference: YEJSO 2878

To appear in: European Journal of Surgical Oncology

Accepted Date: 6 August 2009

Please cite this article as: Barner-Rasmussen I, Popov P, Böhling T, Blomqvist C, Tukiainen E. Microvascular reconstructions after extensive soft tissue sarcoma resections in the upper limb, European Journal of Surgical Oncology (2009), doi: 10.1016/j.ejso.2009.08.003

This is a PDF file of an unedited manuscript that has been accepted for publication. As a service to our customers we are providing this early version of the manuscript. The manuscript will undergo copyediting, typesetting, and review of the resulting proof before it is published in its final form. Please note that during the production process errors may be discovered which could affect the content, and all legal disclaimers that apply to the journal pertain. 


\title{
Microvascular reconstructions after extensive soft tissue sarcoma resections in the upper limb
}

\author{
Original article
}

Running head: Free flap reconstruction for sarcoma

\footnotetext{
I. Barner-Rasmussen ${ }^{\mathrm{a}^{*}}$, P. Popov ${ }^{\mathrm{a}}$, T. Böhling ${ }^{\mathrm{b}}$, C. Blomqvist ${ }^{\mathrm{c}}$, E.Tukiainen $^{\mathrm{a}}$

a Department of Plastic Surgery, Töölö Hospital, Helsinki University Central Hospital, PO 266, 00029 HUS, Finland

${ }^{b}$ Department of Pathology, Peijas Hospital, University of Helsinki and HUSLAB, PO 900, 00029 HUS, Finland

${ }^{\mathrm{c}}$ Department of Oncology, Helsinki University Central Hospital, PO 180, 00029 HUS, Finland
}

${ }^{*}$ Corresponding author at

Department of Plastic Surgery, P.O. Box 266, 00029 HUS, Finland

Tel: +358 400 420404; fax: +358 947187570

E-mail adress: ian.barner-rasmussen@helsinki.fi 


\section{Abstract}

Aims: Limb-sparing surgery combined with radiotherapy $(\mathrm{RT})$ is the basis of extremity soft tissue sarcoma (STS) treatment. The aim of this study was to evaluate the results of microvascular reconstruction after extensive tumour resections in the upper extremity.

Methods: 20 patients with STS of the upper extremity were treated with excision and microvascular reconstruction. RT was administered if surgical margins were less than $25 \mathrm{~mm}$. Results were evaluated retrospectively.

Results: 20 free flaps were performed and no flaps were lost. There was no operative mortality, and wound complication rate was $15 \%$. Median follow-up length was 74 months. Five-year local recurrence-free survival was $57 \%$, metastasis-free survival $67 \%$, disease-free survival $45 \%$ and disease-specific overall survival $80 \%$. Ten patients had no or only mild impairment of upper extremity function, seven had impaired function affecting daily life, and three patients underwent amputation. For patients treated with curative intent, limb salvage rate was $94 \%$.

Conclusions: Free flaps are useful and reliable in the treatment of patients with STS of the upper extremity. Without microvascular reconstruction limb salvage would have been impossible in these patients. Oncological outcome is comparable to other extremity STS patients and upper extremity function is acceptable.

Keywords: Sarcoma; Reconstructive surgery; Surgical flaps; Upper extremity; Microsurgery; Replantation 


\section{Introduction}

Soft tissue sarcomas (STS) are a rare, heterogeneous group of tumours. In 2000-2005 the mean age-adjusted incidence rate of STS in Finland was 2.0/100 000, accounting for less than one per cent of adult malignancies [1]. 12 to 15 per cent of STS are located in the upper extremity $[2,3]$.

In the past, extremity STS was often treated with amputation due to high rates of local recurrence after simple resection [4,5]. Today, using a combination of surgery and radiotherapy $(\mathrm{RT})$, better functional results are achieved with equal rates of local control $[6,7]$. Modern treatment consists of a multidisciplinary team approach, and limb-sparing surgery combined with oncological treatment [8].

The required surgical margins of $2-3 \mathrm{~cm}$ [9] of tumour-free tissue frequently cause large defects, and local or free flaps are often required to achieve tension-free wound closure or to reconstruct tissue defects. Free flap reconstruction is needed in $11-18 \%$ of patients undergoing limb-sparing surgery for upper extremity STS [10-12].

Limb salvage is not always possible, and sometimes amputation is unavoidable [13]. For selected cases of proximal upper extremity or shoulder girdle tumours, even forequarteramputation is used for curation or for palliative treatment [14]. When simultaneous chest wall reconstruction is necessary, fillet flaps from the amputated extremity are useful for reconstruction $[15,16]$. For tumours requiring segmental resection of an extremity, heterotopic replantation has been used [17].

The aim of this study was to evaluate the results of a single institution in using microvascular reconstruction for extensive bone and soft tissue defects after tumour resections in the upper extremity. 


\section{Patients and methods}

Patients treated by the Helsinki University Central Hospital $(\mathrm{HUCH})$ soft tissue sarcoma group who had undergone microsurgical reconstruction after upper limb soft tissue tumour surgery in 1990-2006 were identified, and their medical records retrospectively reviewed. Data concerning patient demographics, tumour characteristics, surgical treatment and oncologic and functional outcome were collected from hospital records

\section{Sarcoma group protocol}

Preoperatively, diagnosis is confirmed by fine or core-needle biopsies, and radiological examinations (CT, MRI) performed to define local and systemic status of the disease. Before sample fixation the pathologist measures tumour size and final histopathological examination is then carried out. STS malignancy grading is based on a four-tiered grading system used by the Scandinavian Sarcoma Group. Grades 1-2 are considered low malignancy grade, and 3-4 are considered high grade. Based on the work of Broders, the system considers cellularity, cell and nuclear polymorphism, differentiation, necrosis, haemorrhage, mitotic activity, and growth pattern for tumour grading $[18,19]$.

Wide microscopical margins are defined as $\geq 25 \mathrm{~mm}$ of healthy tissue or an intact fascial barrier separating the tumour from the excision margin. When margins are less than wide but no tumour cells are found at the edges of the specimen, excision is defined as marginal. Intralesional margins should lead to re-excision in patients treated with curative intent. After marginal excision, external beam radiotherapy (EBRT) is delivered to the operative field with a dose of 50 Gy during 5 weeks. Selected patients receive adjuvant chemotherapy.

Follow-up time was five years for STS patients provided there were no recurrences. Patients with high-grade disease were examined every second month for the first two years, and then every six months. Follow-up protocol for low-grade disease was clinical examination 
two to three times annually. A chest X-ray was taken at each visit. A CT or MRI scan of the operative area was performed annually, beginning at six months postoperatively.

\section{Patient material}

In 1987-2006 the HUCH soft tissue sarcoma group treated 1314 STS patients, of which 204 had upper extremity tumours. 24 of upper extremity STS patients were treated with primary amputation, and direct closure after tumour excision was done in 82 patients. Reconstructive procedures were skin graft in 28 , pedicled skin flap in 15 and pedicled muscle flap in 33 patients. 20 patients required microvascular reconstruction after soft-tissue tumour excision, and they were included in this study (Table 1). Two patients had palliative procedures for metastasized STS, and they were excluded from oncologic analyses, but included in analyses for surgical endpoints and functional outcome. Two patients, one with dermatofibrosarcoma protuberans (DFSP) and the other with desmoid tumour, were also excluded from oncologic analyses but included in surgical endpoint and functional outcome analyses. 16 patients thus remained for analysis of oncologic endpoints.

In all, there were 20 patients ( 4 male, 16 female) with a median age of 61 years. Seven patients were referred for virgin primary tumours and six for primary tumours after intralesional operation. Seven patients were admitted for recurrent tumours.

\section{Tumour characteristics}

Median tumour size was $5.0 \mathrm{~cm}$ (range 1.8-29.0). Excluding the two patients treated with palliative intent, all tumours were less than $10.0 \mathrm{~cm}$ in diameter. 16 soft tissue sarcomas were of high malignancy grade and two were of low grade. 17 tumours were extracompartmental and three were intracompartmental; all of the intracompartmental tumours were subcutaneous. 
16 tumours were located distal to the elbow joint. In one patient the joint was affected and in three cases the tumour was located above elbow level. Malignant fibrous histiocytoma (MFH) was the most common histological STS subtype, present in ten cases. Other diagnoses were two fibrosarcomas, two synovial sarcomas, and one sarcoma NOS, extraskeletal chondrosarcoma, epitheloid sarcoma and malignant peripheral nerve sheath tumour (MPNST).

\section{Reconstructive procedures}

All operations were performed as single-stage procedures. Simple tumour excision and microvascular reconstruction of the defect was done for 17 patients. The free flap contained bone in three of these. Two forequarter-amputations with fillet flaps from the amputated extremity were performed. In one of these, the fillet flap was also used for chest wall reconstruction. In addition, a patient with synovial sarcoma affecting the elbow joint had replantation of the distal forearm to the upper arm after segmental resection of the elbow area.

Tendon reconstruction was performed in eight cases, and nerve reconstruction in six cases. In addition one latissimus dorsi flap was used as an innervated functional flap, the motor nerve of the flap sutured to the radial nerve at the recipient site. Recipient site skin grafting was necessary in two cases.

Median duration of operation was 310 minutes (range 195-575) and median flap ischemia time was 64 minutes (range 31-216). Median perioperative bleeding was $650 \mathrm{ml}$ (range 1508000). 


\section{Surgical margins}

For curatively treated STS patients, wide microscopical margins were achieved in seven patients, and marginal excision in eight patients. In one patient, final histopathological examination showed intralesional margins, and humeral amputation was performed.

\section{Oncological treatment}

Five patients with wide surgical margins had no oncological treatment. Eight STS patients with marginal excision underwent postoperative external beam radiotherapy (EBRT). In addition, two patients with wide excision received postoperative EBRT. Preoperative radiotherapy was given to one patient with a large, high-grade tumour. This patient was also the only one to receive chemotherapy, which was given both as neoadjuvant and adjuvant treatment. In three cases, including the two palliatively treated patients, EBRT could not be used because of earlier radiotherapy.

Statistical analysis

SPSS for Windows (v 15.0, SPSS Inc., Chicago, Illinois) was used for statistical analysis. Oncologic endpoints were: local recurrence-free survival (LRFS), metastasis-free survival (MFS), disease-free survival (DFS) and disease-specific overall survival (DSOS), calculated by the Kaplan-Meier method. Values refer to outcome at five years. Prognostic factors for surgical complications were analyzed with chi-square- and Fisher's exact test. P-values of $\leq 0.05$ were considered significant. 


\section{Results}

\section{Flap survival and complications}

There was no postoperative mortality and no free flaps were lost. One patient required immediate reoperation for reanastomosis of the flap vein (Patient 17). Another patient underwent donor site haematoma evacuation on the first postoperative day (Patient 7). In one case, reosteosynthesis of the fibula flap was performed the day after the initial operation (Patient 5). Wound revision was necessary in two patients for minor wound complications (Patients 17 and 20). In all, three patients had wound complications requiring one or more operative procedures, giving a wound complication rate of $15 \%$.

One patient with osteoradionecrosis and subsequent fistula at nine months was treated with repeated wound revisions. Successful closure was achieved at 14 months after coverage with a pedicled flap. Later remodelling of the flap was carried out in three cases to achieve a more satisfactory aesthetic or functional result. The patient that had undergone humeroantebrachial replantation had surgery at four months to adjust the position of the replant for better function. No significant prognostic factors predicting surgical complications were identified in statistical analysis.

\section{Oncologic outcome}

Oncologic outcome was analyzed in 16 soft-tissue sarcoma patients treated with curative intention. Median length of follow-up was 74 months (range 19-187). Five-year estimated local recurrence-free survival (LRFS) was 57\%, metastasis-free survival (MFS) 67\% and disease-free survival (DFS) 45\%. Disease-specific overall survival (DSOS) was $80 \%$ at five years (Figure 1).

Seven patients developed a local recurrence at a median of 37 months (range 6-61). Patients with $>5.0 \mathrm{~cm}$ tumours were significantly more likely to have a local recurrence than 
those with $5.0 \mathrm{~cm}$ or smaller tumours (LRFS $20 \%$ vs. $78 \%, \mathrm{P}=0.004$ ). Local recurrence was also more likely for higher-grade tumours; LRFS for grade 2 tumours was $100 \%$, for grade 3 tumours $67 \%$, and for grade 4 tumours $29 \%(P=0.021)$. Metastasis developed in seven patients. Median time to metastasis was 33 months (range 4-117). Seven out of 16 patients have died of disease, at a median of 72 months (range 21-187) after surgery. Tumour size over $5.0 \mathrm{~cm}$ was a significant predictor of disease death (DSOS 60\% vs. $91 \%$ for patients with $0-5.0 \mathrm{~cm}$ tumours, $\mathrm{P}=0.028$ )

The two patients who underwent palliative surgery for advanced STS both died from disease, at two and 13 months. The two patients operated for DFSP and desmoid tumour are both disease free at a 112 and 133 months, respectively.

Functional outcome

Eight patients experienced no impairment of function in the upper extremity during followup. Two patients experienced some impairment of function not affecting daily activities. Seven patients had impaired upper extremity function significantly affecting daily activities. Two patients underwent planned primary forequarter amputation, and humeral amputation was performed in one patient due to intralesional surgical margins.

Because of local recurrences at one, two and four years after free flap sarcoma surgery, late amputations were necessary in three patients. Excluding the two planned forequarter amputations this gives an early limb salvage rate of $94 \%$, and $78 \%$ limb salvage rate at five years. In all, five amputations were performed in curatively treated patients. 


\section{Discussion}

Soft tissue sarcoma of the upper extremity is rare; only few cases are encountered annually in Finland with 5.3 million inhabitants [1]. Microvascular reconstructive surgery after sarcoma resection is required in a significant proportion of these patients, but remains a procedure that few surgeons become familiar with. This is, to our knowledge, the largest series to date on upper extremity STS focusing on limb salvage and free flap reconstruction.

Limb salvage and upper extremity reconstruction

Oncologically safe surgical margins, preserving a functional limb and a good aesthetic result are the goals of limb salvage surgery for STS. Limb salvage does not adversely affect oncological outcome [6,7], and the functional benefits of limb salvage with soft tissue reconstruction in sarcoma surgery have been established [20]. Free flaps provide wellvascularised tissue facilitating wound healing, and also tolerate radiotherapy well. In addition, no further morbidity is caused to the extremity. A wide array of free flaps is available for reconstruction following upper extremity tumour resection, and the choice of flap is based on defect size, types of tissue required, postoperative functional goal, and surgeon preference. For reconstruction of long segments of bone, the free fibular flap is preferred [21,22].

\section{Disease recurrence and survival}

Follow-up in this series was long, with a median follow-up of 74 months, attributable to the centralized care of these patients. Oncological results were comparable to studies with similar patient material [9]. Other works on upper extremity STS have reported rates of local recurrence of $17-25 \%$ with variable lengths of follow up $[11,12,23]$. In a study including 80 patients with STS of the upper extremity treated at the authors' institution between 1987 and 1999, local recurrence was less common (LRFS 79\%), but MFS and DSOS were comparable to the present study [12]. Only $19 \%$ of patients in the earlier study presented with recurrent tumour compared to $35 \%$ in this series, which may explain our higher rate of local recurrence; 
local recurrence at presentation has been shown to predict further local recurrences [24]. Kim et al reported their results in treating 17 patients with limb salvage and microvascular reconstruction [10]. We have reported very similar outcomes, the slightly lower LRFS and DSOS (50.0 and $61.3 \%$, respectively) of Kim et al likely explained by their more challenging patient material with mostly high-grade, recurrent sarcomas.

\section{Functional outcome}

A variety of scoring systems have been used for functional evaluation after upper extremity tumour surgery $[25,26]$. Limb salvage and microvascular reconstruction did not adversely affect functional outcome in a previous study after upper extremity STS resection [27]. Due to the retrospective nature of this study, quantitative tools for assessment of functional outcome were unavailable, but the majority of our patients experienced normal or only mildly impaired upper extremity function.

\section{Further treatment options}

In the future, techniques like composite tissue allotransplantation, or advanced myolectric prostheses, combined with targeted reinnervation surgery, or dielectric elastomers [28-30] could provide us with readily available, easy-to-use components for reconstruction of the upper extremity. At present these remain, however, experimental techniques, and locally available tissue, or of pedicled or free flaps must be used for reconstruction. 


\section{Conclusions}

When tension-free wound closure and cavity filling after STS surgery cannot be achieved using locally available soft tissues, microvascular reconstruction is needed. Free flaps provide well-vascularised tissue to the site, promoting wound healing and thus facilitating early administration of oncological treatment. Microvascular reconstruction is safe and reliable for defects after soft tissue sarcoma resection, and functional outcome is generally good. Due to the rarity of these procedures, treatment should be planned and carried out in centres with the necessary multidisciplinary resources. 


\section{Acknowledgements}

The first author was supported by a research grant from The Luise and Henrik Kuningas Foundation while working on this article. The funding source had no role in the preparation of the manuscript. 
Figure captions:

Figure 1. Outcome for 16 soft tissue sarcoma patients treated with limb salvage and microvascular reconstruction with curative intent. DSOS = disease-specific overall survival, MFS $=$ metastasis-free survival, LRFS $=$ local recurrence-free survival. 
${ }^{1}$ Finnish Cancer Registry. Cancer in Finland 2004 and 2005. Cancer Society of Finland, Publication No. 72. Helsinki, 2007.

${ }^{2}$ Nijhuis PH, Schaapveld M, Otter R, Molenaar WM, van der Graaf WT, Hoekstra HJ.

Epidemiological aspects of soft-tissue sarcomas (STS) - consequences for the design of clinical STS trials. Eur J Cancer 1999; 35: 1705-10.

${ }^{3}$ Pollock RE, Karnell LH, Menck HR, Winchester DP. The National Cancer Data Base report on soft tissue sarcoma. Cancer 1996; 78: 2247-57.

${ }^{4}$ Cantin J, McNeer GP, Chu FC, Booher RJ. The problem of local recurrence after treatment of soft tissue sarcoma. Ann Surg 1968; 168: 47-53.

${ }^{5}$ Hoekstra HJ, Thijssens K, van Ginkel RJ. Role of surgery as primary treatment and as intervention in the multidisciplinary treatment of soft tissue sarcoma. Ann Oncol 2004; 15: 181-6.

${ }^{6}$ Rosenberg SA, Tepper J, Glatstein E, Costa J, Baker A, Brennan M et al. The treatment of soft-tissue sarcomas of the extremities: prospective randomized evaluations of (1) limb-sparing surgery plus radiation therapy compared with amputation and (2) the role of adjuvant chemotherapy. Ann Surg 1982; 196: 305-15.

${ }^{7}$ Yang JC, Chang AE, Baker AR, Sindelar WF, Danforth DN, Topalian SL et al. Randomized prospective stydy of the benefit of adjuvant radiotherapy in the treatment of soft tissue sarcomas of the extremity. J Clin Oncol 1998; 16: 197-203.

${ }^{8}$ Clark MA, Fisher C, Judson I, Thomas JM. Soft-tissue sarcomas in adults. N Engl J Med 2005; 353: 701-11.

${ }^{9}$ Sampo M, Tarkkanen M, Huuhtanen R, Tukiainen E, Böhling T, Blomqvist C. Impact of the smallest surgical margin on local control in soft-tissue sarcoma. Br J Surg 2008; 95: 237-43.

${ }^{10}$ Kim JY, Subramanian V, Yousef A, Rogers BA, Robb GL, Chang DW. Upper extremity limb salvage with microvascular reconstruction in patients with advanced sarcoma. Plast Reconstr Surg 2004; 114: 400-8.

${ }^{11}$ Lohman RF, Nabawi AS, Reece GP, Pollock RE, Evans GR. Soft tissue sarcoma of the upper extremity: a 5-year experience at two institutions emphasizing the role of soft tissue flap reconstruction. Cancer 2002; 94: 2256-64. 
${ }^{12}$ Popov P, Tukiainen E, Asko-Seljavaara S, Huuhtanen R, Virolainen M, Virkkunen P et al. Soft tissue sarcomas of the lower extremity: surgical treatment and outcome. Eur J Surg Oncol 2000; 7: 679-85.

${ }^{13}$ Clark MA, Thomas JM. Amputation for soft-tissue sarcoma. Lancet Oncol 2003; 4: 335-42.

${ }^{14}$ Clark MA, Thomas JM. Major amputation for soft-tissue sarcoma. Br J Surg 2003; 90: 102-7.

${ }^{15}$ Tran NV, Evans GR, Kroll SS, Reece GP, Ainsle N, Robb GL. Free fillet extremity flap: indications and options for reconstruction. Plast Reconstr Surg 2000; 105: 99-104.

${ }^{16}$ Cordeiro PG, Santamaria E, Hidalgo D. The role of microsurgery in reconstruction of oncologic chest wall defects. Plast Reconstr Surg 2001; 108: 1924-30.

${ }^{17}$ Windhager R, Millesi H, Kotz R. Resection-replantation for primary malignant tumours of the arm. An alternative to fore-quarter amputation. J Bone Joint Surg Br 1995; 77: 176-84.

${ }^{18}$ Angervall L, Kindblom LG. Principles for pathologic-anatomic diagnosis and classification if softtissue sarcomas. Clin Orthop 1993; 289: 9-18.

${ }^{19}$ Broders AC, Hargrave R, Meyerding HW. Pathologic features of soft tissue fibrosarcoma with special reference to the grading of its malignancy. Surg Gynaecol Obstet 1939; 69: 267-280.

${ }^{20}$ Serletti JM, Carras AJ, O’Keefe RJ, Rosier RN. Functional outcome after soft-tissue reconstruction for limb salvage after sarcoma surgery. Plast Reconstr Surg 1998; 102: 1576-83.

${ }^{21}$ Saint-Cyr M, Langstein HN. Reconstruction of the hand and upper extremity after tumor resection. $J$ Surg Oncol 2006; 94: 490-503.

${ }^{22}$ Pederson WC. Upper extremity microsurgery. Plast Reconstr Surg 2001; 107: 1524-36.

${ }^{23}$ Herbert SH, Corn BW, Solin LJ, Lanciano RM, Schultz DJ, McKenna WG, Coia LR. Limbpreserving treatment for soft-tissue sarcomas of the extremities. The significance of surgical margins. Cancer 1993; 72: 1230-8.

${ }^{24}$ Pisters PW, Leung DH, Woodruff J, Shi W, Brennan MF. Analysis of prognostic factors in 1,041 patients with localized soft tissue sarcomas of the extremities. J Clin Oncol 1996; 14: 1679-89.

${ }^{25}$ Wright EH, Gwilym S, Gibbons CL, Critchley P, Giele HP. Functional and Oncological outcomes after limb-salvage surgery for primary sarcomas of the upper limb. J Plast Reconstr Aesthet Surg 2008; 61: 382-7.

${ }^{26}$ Hoy E, Granick M, Benevenia J, Patterson F, Datiashvili R, Bille B. Reconstruction of musculoskeletal defects following oncologic resection in 76 patients. Ann Plast Surg 2006; 57: 190-4. 
${ }^{27}$ Kim JY, Youssef A, Subramanian V, Rogers BA, Pollock RE, Robb GL, Chang DW. Upper extremity reconstruction following reconstruction of soft tissue sarcomas: a functional outcomes analysis. Ann Surg Oncol 2004; 11: 921-7.

${ }^{28}$ Swearingen B, Ravindra K, Xu H, Wu S, Breidenbach WC, Ildstad ST. Science of composite tissue allotransplantation. Transplantation 2008; 86: 627-35.

${ }^{29}$ Miller LA, Stubblefield KA, Lipschuttz RD, Lock BA, Kuiken TA. Improved myoelectric prosthesis control using targeted reinnervation surgery: a case series. IEEE Trans Neural Syst Rehabil Eng 2008; 16: $46-50$.

${ }^{30}$ Biddiss E, Chau T. Dielectric elastomers as actuators for upper limb prosthetics: challenges and opportunities. Med Eng Phys 2008; 30: 403-18. 


\section{Conflict of interest statement}

The authors declare that they have no conflict of interest. 
Table 1

Patient and tumour characteristics

\begin{tabular}{|c|c|c|c|c|c|c|}
\hline Patient & Tumour histology & Grade & Size & Free flap & DSOS (months) & Status \\
\hline $1^{\mathrm{a}}$ & MFH & 4 & 20.0 & latissimus dorsi & 2 & DOD \\
\hline $2^{\mathrm{a}}$ & extraskeletal chondrosarcoma & 3 & 29.0 & fillet (antebrachium) ${ }^{\mathrm{b}}$ & 13 & DOD \\
\hline 3 & MFH & 4 & 8.0 & fillet (antebrachium) ${ }^{\mathrm{b}}$ & 26 & DOD \\
\hline 4 & MFH & 4 & 4.5 & tensor fascia latae & 31 & DUC \\
\hline 5 & MFH & 4 & 7.0 & fibula & 40 & DOD \\
\hline 6 & sarcoma NOS & 2 & 1.8 & scapular & 87 & NED \\
\hline 7 & $\mathrm{MFH}$ & 4 & 6.0 & latissimus dorsi & 58 & NED \\
\hline 8 & synovial sarcoma & 3 & 5.0 & antebrachial replantation & 21 & DOD \\
\hline 9 & fibrosarcoma & 3 & 6.0 & radial forearm & 72 & DOD \\
\hline 10 & MFH & 4 & 9.0 & tensor fascia latae & 62 & DUC \\
\hline 11 & MFH (myxoid) & 2 & 5.0 & radial forearm & 76 & NED \\
\hline 12 & MPNST & 4 & 2.5 & anterolateral thigh & 31 & NED \\
\hline 13 & epitheloid sarcoma & 3 & 3.0 & latissimus dorsi & 187 & DOD \\
\hline 14 & synovial sarcoma & 3 & 3.0 & fibula & 165 & NED \\
\hline 15 & desmoid tumor ${ }^{c}$ & - & 5.8 & scapular & 112 & NED \\
\hline 16 & MFH & 3 & 2.5 & radial forearm & 96 & NED \\
\hline 17 & $\mathrm{MFH}$ & 4 & 4.5 & latissimus dorsi & 155 & NED \\
\hline 18 & $\mathrm{MFH}$ & 3 & 4.5 & tensor fascia latae + crista iliaca & 145 & DOD \\
\hline 19 & $\mathrm{DFSP}^{\mathrm{c}}$ & 1 & 3.0 & radial forearm & 133 & NED \\
\hline 20 & fibrosarcoma & 3 & 5.0 & latissimus dorsi & 130 & DOD \\
\hline
\end{tabular}

MFH: malignant fibrous histiocytoma, NOS: not otherwise specified, MPNST: malignant peripheral nerve sheath tumour, DFSP: dermatofibrosarcoma protuberans. DSOS: disease-specific overall survival. DOD: dead of disease, DUC: dead of unrelated cause, NED: no evidence of disease.

${ }^{a}$ Palliative treatment intent. ${ }^{b}$ Primary amputation. ${ }^{c}$ Non-sarcoma, excluded from oncological endpoint analyses. 


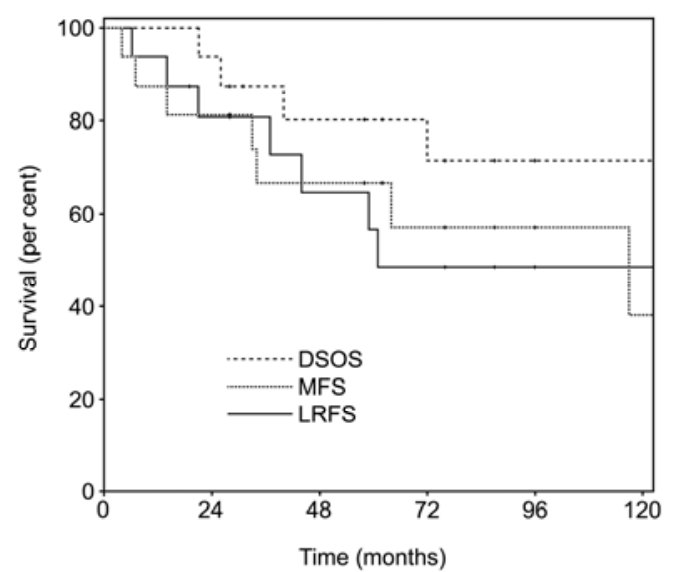

